\title{
Atenção Farmacêutica e Atenção Flutuante: formações de compromisso entre Farmácia e Psicanálise
}

\author{
Pharmaceutical care and suspended attention: \\ compromise-formations between pharmacy and psychoanalysis
}

Marcelo de Pádula ${ }^{1}$

Alicia Viviana Pinto ${ }^{2}$

Guacira Corrêa de Matos ${ }^{3}$

Danielle Tavares Siqueira ${ }^{4}$

Roberta Claudio Vieira ${ }^{5}$

\footnotetext{
${ }^{1}$ Departamento de Análises Clínicas e Toxicológicas, Faculdade de Farmácia, Universidade Federal do Rio de Janeiro. Av. Carlos Chagas Filho 373/CCS/ Bloco $\mathrm{A} / 2^{\circ}$ andar/sala 42 , Cidade Universitária. 21.941-902 Rio de Janeiro RJ Brasil. marcelo@pharma.ufrj.br ${ }^{2}$ Instituto Nacional de Controle de Qualidade em Saúde, Fundação Oswaldo Cruz.

${ }^{3}$ Departamento de Fármacos e Medicamentos, Faculdade de Farmácia, Universidade Federal do Rio de Janeiro.

${ }^{4}$ Círculo Psicanalítico do Rio de Janeiro (CPRJ). ${ }^{5}$ Instituto Estadual de Hematologia Arthur de Siqueira Cavalcanti.
}

\begin{abstract}
This paper presents an interdisciplinary overview of the rational use of medicine from a metapsychological standpoint. The need to reinstate the activity of the pharmaceutical professionals vis-à-vis their patients through pharmaceutical care demands the intervention of new know-how that can ensure a revitalization of this human relationship. In this sense, by means of a compilation of passages from the works of Freud, some of the most important metapsychological concepts were presented: psychic apparatus, evenly hovering attention and commitment formations. These concepts were then presented as an applicable theoretical tool for qualitative analysis in pharmaceutical care, though especially for participant observation. Thus, the main objective was to provide new tools for the pharmacists in terms of listening and receptivity, which can enhance their professional routine regarding the relationship with their patients, as well as in the gathering and interpretation of qualitative data concerning human issues involving pharmaceutical care.
\end{abstract}

Key words Pharmaceutical care, Medicine, Psychoanalysis, Qualitative analysis - methodology, Participant observation
Resumo O presente trabalho apresenta uma visão interdisciplinar do uso racional do medicamento a partir de uma perspectiva metapsicológica. A necessidade de resgate da atuação do profissional farmacêutico junto ao paciente, através da Atenção Farmacêutica, demanda a intervenção de novos saberes que possam proporcionar uma revitalização desta relação humana. Neste sentido, através de uma compilação de passagens da obra freudiana, foram apresentados alguns dos principais conceitos metapsicológicos: aparelho psíquico, atenção flutuante e formações de compromisso. Tais conceitos foram então apresentados como ferramenta teórica articulável com análises qualitativas em Atenção Farmacêutica, mais particularmente com a observação participante. Assim, os objetivos principais foram de fornecer ao farmacêutico novas ferramentas de escuta $e$ acolhimento que podem aprimorar a atuação profissional na relação com seu paciente, assim como na obtenção e interpretação de dados qualitativos relacionados às questões humanas envolvidas nas pesquisas em Atenção Farmacêutica.

Palavras-chave Atenção Farmacêutica, Medicamento, Psicanálise, Análise qualitativa - metodologia, Observação participante 


\section{Introdução}

De acordo com o Ministério de Educação brasileiro o farmacêutico deve atuar multiprofissionalmente, interdisciplinarmente e transdisciplinarmente com extrema produtividade na promoção da saúde baseado na conviç̧ão científica, de cidadania e ética ${ }^{1}$.

Neste sentido, a promoção da saúde ${ }^{2}$ configura importante interface comum entre os objetivos dos profissionais da Psicologia e de Farmácia. Para Leite ${ }^{3}$, no caso da participação do farmacêutico, existem três eixos principais em torno da promoção da saúde a serem contemplados: (i) reorientação dos serviços de farmácia, (ii) desenvolvimento de habilidades da comunidade e (iii) incentivo à ação comunitária. Assim, tais eixos podem ser desenvolvidos tomando-se a relação com o paciente como ponto comum no exercício cotidiano de suas profissões: o psicólogo na clínica e o farmacêutico na farmácia, uma vez que o tipo de relação que o paciente tem com seu farmacêutico vai determinar maior ou menor adesão a uma dada terapia medicamentosa.

Uma atribuição do Farmacêutico que demonstra a estreita relação de saberes que permeia ambas as profissões é a Atenção Farmacêutica. Neste sentido, dados da Organização Mundial da Saúde (OMS) indicam que mais de $50 \%$ de todos os medicamentos são prescritos, dispensados ou vendidos inapropriadamente e que cerca da metade dos pacientes não os usa corretamente $^{4,5}$. O farmacêutico deixara de ser um prestador de assistência e se tornara um comerciante de medicamentos. O novo modelo de Atenção Farmacêutica vem em resposta ao resgate da função assistencial farmacêutica ${ }^{6}$. O benefício da implantação deste novo modelo está no restabelecimento da relação terapêutica entre farmacêutico e paciente. A Atenção Farmacêutica inclui diversos elementos: afirmação de uma necessidade social; enfoque centrado no paciente e suas necessidades; assistência à pessoa mediante uma relação terapêutica e descrição das responsabilidades concretas do profissional ${ }^{7}$.

A proposta de Consenso Brasileiro sobre Atenção Farmacêutica e, consequentemente, sobre o papel do farmacêutico compreende “...atitudes, ética, comportamentos, habilidades, compromissos e corresponsabilidades na prevenção de doenças, promoção e recuperação da saúde, integradas à equipe de saúde...”. Também figura a “...interação que deve envolver as concepções dos seus sujeitos, respeitadas as suas especificidades biopsicossociais, sob a ótica da integralidade das ações de saúde" ${ }^{34,8}$.
A ideia de se propor Metapsicologia Freudiana ${ }^{9}$ como saber $p s i$ a ser articulado com Atenção Farmacêutica deriva de uma interpretação do binômio paciente/farmacêutico que está além das possíveis influências conscientes que possam reger esta relação. Diante da atual preocupação com iniciativas de humanização, com um processo de subjetivação das relações ${ }^{10,11}$, não se pode deixar de pensar as possíveis aplicações dos saberes metapsicológicos freudianos na relação paciente/farmacêutico.

A Metapsicologia Freudiana principalmente compreende o que, na descrição do aparelho psíquico humano, se define como o inconsciente ${ }^{9}$. Deste modo, o termo metapsicologia passou a caracterizar a descrição de um processo psíquico nas suas relações dinâmicas, tópicas e econômi$\operatorname{cas}^{9,12}$. Ou seja, o aparelho psíquico humano possui instâncias (aspecto tópico): Id, Ego e Superego ${ }^{9}$. Também prevê o jogo constante de descargas de energia, num balanço de Prazer/Desprazer (aspecto dinâmico) a fim de manter baixo o nível de Tensão do aparelho psíquico (aspecto econômico). Porém, estes processos não se dão livremente, em função do processo de recalcamento $^{9,13}$. Este é responsável pela manutenção, entre outros, de representações inconscientes que seriam de caráter insuportável para o ego, mas que não deixam de causar tensão no aparelho psíquico. Portanto, o desejável equilíbrio do aparelho psíquico, envolvendo as relações de tensão, prazer e desprazer é de difícil consecução e geralmente provoca saídas alternativas, cujos destinos ou metas nem sempre são aquelas contidas originalmente no inconscient $e^{9,13}$.

Desta forma, o presente trabalho pretende demonstrar como os constructos da metapsicologia podem servir como ferramentas úteis para a obtenção e interpretação de dados qualitativos (dentro de um contexto metodológico qualitativo) e suprir à Atenção Farmacêutica de informações complementares sobre as relações pacientefarmacêutico, paciente-medicamento e também em estudos que procuram respostas para alguns desafios envolvidos na implantação de um modelo de Atenção Farmacêutica.

A Metodologia Qualitativa, extremamente relevante para o campo da Atenção Farmacêuti$\mathrm{ca}^{14}$ envolve investigações que produzem dados descritivos, como as palavras das pessoas (ditas ou escritas) e a conduta/comportamento observável ${ }^{15}$. Esta metodologia também apresenta caráter humanista, uma vez que busca a compreensão das pessoas dentro de um marco referenciado no próprio indivíduo, valorizando os ce- 
nários e as pessoas ${ }^{14}$. Dentre as diversas técnicas existentes para a obtenção de dados na investigação qualitativa, as práticas mais representativas envolvem a observação participante, a entrevista em profundidade e os grupos de discussão, um triângulo qualitativo ${ }^{16}$. O principal uso da observação participante encontra-se no estudo daquilo que escapa à norma e ao discurso normal, ao que ainda não se entende, ao incipiente, a outras culturas, aos grupos semiocultos ou clandestinos e ao que tende a encerrar-se entre os muros das instituições, mas que se manifesta ${ }^{16}$.

Apesar da sua importância para a Atenção Farmacêutica, a aplicação da Metodologia Qualitativa de investigação em farmácia constitui, por si só, um desafio para o Farmacêutico ${ }^{14}$, uma vez que a consecução destas técnicas pressupõe uma formação em disciplinas que estudem as pessoas e seus sistemas de sociedade. Assim, mesmo com a crucial participação da Farmácia Social que trata o medicamento desde uma perspectiva das ciências sociais e humanísticas ${ }^{17}$, aspectos importantes de ordem subjetiva podem ser negligenciados ou mesmo despercebidos pelo profissional farmacêutico.

Esta preocupação se encontra muito bem caracterizada por Javier Callego Gallego ${ }^{16}$ em um contexto social e coletivo, e que possui dimensão articulável com questões individuais, inclusive de ordem inconsciente. Neste ponto, propõe-se uma visão desta mesma preocupação de Gallego, mas agora focada no nível subjetivo, na qual o cenário de estudo passa a ser o indivíduo, e ao que escapa à norma e ao discurso normal (consciente): o incipiente, o semioculto (ou totalmente), encerrado no inconsciente pelos muros do processo de recalcamento $^{9,13}$. Desta forma, dentro do campo da observação participante, serão analisadas as contribuições da introdução de conceitos e técnicas metapsicológicas valiosas para a obtenção e interpretação de dados qualitativos fundamentais em estudos de subjetividade, tanto do paciente quanto do próprio farmacêutico envolvido na Atenção Farmacêutica.

\section{Da Atenção Flutuante à Atenção Farmacêutica}

Mais do que traçar um paralelo entre estas Atenções, o escopo aqui é o de apresentar a Atenção Flutuante (ou uniformemente suspensa) ao farmacêutico como uma ferramenta clínica de escuta aplicável aos estudos qualitativos que envolvam a observação participante durante o exercício da Atenção Farmacêutica.
A técnica de observação participante sugere o afastamento de crenças e predisposições pessoais do profissional, valorizando assim os cenários e as pessoas ${ }^{14}$. A técnica de Atenção Flutuante, apresentada por Freud ${ }^{18}$ como recomendação aos médicos que praticassem a psicanálise, preconiza uma escuta neutra do profissional que não deve privilegiar, em princípio, qualquer parte do discurso do paciente. Deste modo, não há a recomendação restritiva para que o observador/ analista se afaste de suas crenças ou convicções mas que as coloque em suspensão. Assim, enquanto o afastamento pressupõe a não participação de aspectos na escuta (e juízo) tais como inclinações pessoais, preconceitos, pressupostos teóricos, entre outros ${ }^{18}$, a suspensão aponta para o reconhecimento da existência de tais convicções no observador e suas possíveis influências transferenciais na relação observador/observado (analista/paciente) ${ }^{18}$.

Neste sentido, no observador existe uma dimensão inconsciente que também atua na recepção dos conteúdos apresentados pelo seu paciente (observado). Assim, há uma oposição entre a neutralidade científica e neutralidade analítica: enquanto na neutralidade científica se busca controlar e eliminar o que interfere em um dado processo, na neutralidade analítica se faz justamente daquilo que interfere no processo, o seu maior objeto de estudo ${ }^{19}$. Gallego já assinala um exemplo fundamental de "observar e participar" (ruído contraditório) necessário para o sucesso da observação participante que possui característica epistemológica comum a um valor intrínseco do inconsciente: a atemporalidade ${ }^{13,16}$.

A integração do observador na vida cotidiana do grupo é fundamental para que a observação participante possa captar plenamente o que se passa nos espaços sociais e tal integração pode ser considerada um espaço sem tempo ${ }^{16}$. Se a noção de atemporalidade já é admitida e preconizada nesta escala, não é difícil adaptar uma versão da observação participante definida por Taylor e Bogdan ${ }^{20}$ que inclua ares metapsicológicos: a interação entre inconsciente observador e inconsciente observado no espaço (atemporal) deste último (paciente). Neste contexto e desde a perspectiva da Atenção Flutuante, a comunicação se dá entre dois inconscientes ligados, na qual o inconsciente do analista se coloca como receptor do inconsciente do paciente ${ }^{18}$. Destaca-se então, que em uma dimensão de observação individual participante, em lugar de tentar descartar o ruído existente e causado pela presença de um observador no meio observado, que o Farmacêuti- 
co possa estar preparado para, em concomitância à prática Social, incluir estes conteúdos em seu estudo.

Adicionalmente, o farmacêutico deve se colocar em um estado tal que valorize aquilo que lhe chega dissimulado pelo inconsciente do paciente, em condições de estar suscetível e permeável ao aspecto subjetivo, e às vezes inacessível à consciência do discurso daquele que fala. O Farmacêutico deve estar apto a escutar tudo o que lhe é comunicado pelo paciente (sem substituir ou privilegiar). A expressão do paciente em modo de "associação livre", por sua vez, prevê que ele deva ser colocado em uma posição na qual possa contar ao observador tudo o que lhe passa pela mente, livre de todas as objeções e afetos que possam implicar em uma escolha ${ }^{21}$. Diante disto, a análise dos conteúdos inconscientes é possível pela técnica da Atenção Flutuante que encontra suporte metodológico em um dos vértices do triangulo qualitativo: a observação participante. Ao permitir que seu paciente fale livremente, o Farmacêutico estará mais propenso a receber os elementos que lhe chegam dele. Em outros termos, se os elementos inconscientes surgem a partir de múltiplas deformações, como se verá adiante, a sintonia da escuta do Farmacêutico modulada para Atenção Flutuante permitirá a recepção destes elementos emitidos pelo seu paciente.

A necessidade de disfarce ou dissimulação pode ser facilmente compreendida admitindo-se que parte dos conteúdos inconscientes é aí mantida pela ação do processo de recalcamento (vide introdução). Apesar de estes conteúdos poderem ser de caráter insuportável (angustiantes) para o ego, eles permanecem continuamente exercendo pressão contra o recalcamento (censura), na direção da consciência. Assim, o disfarce é a forma assumida pelo conteúdo recalcado para tentar facilitar sua chegada até a consciência. Tal disfarce não só torna o conteúdo inconsciente irreconhecível à consciência, mas serve para, em um único compromisso, atender simultaneamente o desejo inconsciente e as exigências defensivas da censura $^{12}$.

Aqui se chega ao conceito das formações de compromisso, também conhecidas como formações do inconsciente, na releitura de Jacques La$\operatorname{can}^{22}$, e que nada mais são do que um acordo (compromisso) entre as representações recalcadas e aquelas recalcantes ${ }^{9}$. Alguns exemplos práticos de formações para o Farmacêutico que serão vistos a seguir: atos falhos e chistes representam, muitas das vezes, pequenos detalhes de um discurso, mas que podem estar revestidos ou impregnados dos conteúdos inconscientes mais relevantes de um sujeito.

\section{Algumas formações de compromisso do ato falho}

$\mathrm{O}$ ato falho (Fehlleistung) representa uma formação de compromisso que permeia com frequência todo e qualquer cenário da vida cotidiana de um sujeito. $\mathrm{O}$ ato falho indica um ato em que o resultado especificamente buscado não é atingido, mas aparece substituído por outro. Não serve para designar falhas da palavra, da memória ou da ação, mas para aquilo que o sujeito habitualmente consegue fazer bem, e cujo fracasso tende a atribuir a uma banal distração ou ao acaso ${ }^{12}$. Porém, do ponto de vista inconsciente, o ato falho é um ato bem-sucedido, seu caráter de formação de compromisso o explica: o aparente erro ou insucesso na ação serve de disfarce para que o conteúdo inconsciente possa emergir sem maiores problemas para a censu$\mathrm{ra}^{12}$. De forma geral, ato falho engloba um sentido amplo de ações, como todos os tipos de erros, lapsos e esquecimentos. Alguns tipos de atos falhos descritos por Freud ${ }^{23}$ merecem comentário, uma vez que servirão para ilustrar ao Farmacêutico a riqueza do trabalho do aparelho psíquico em dissimular e enviar mensagens à consciência.

Tanto o ato de fala quanto o que é colocado em ato de silêncio são determinados por conteúdos inconscientes e, portanto, considerados mensagens enviadas de um sujeito para outro, mesmo que tais mensagens peguem o próprio sujeito de surpresa ${ }^{24}$.

Nos atos falhos ligados ao esquecimento de nomes próprios, Freud ressalta que, com frequência, o nome lembrado que vem à mente do sujeito é errado. Isto evidenciaria a existência de um processo de deslocamento atrelado a este esquecimento e lembrança; o nome errado que fora lembrado teria, em algum grau, ligação com o nome esquecido, o que permitiria ao sujeito, mais tarde e amiúde, acabar recordando do nome esquecido $^{23}$.

Da mesma forma pela qual os atos falhos da fala se manifestam, Freud ${ }^{23}$ também dá destaque àqueles ligados às ações. Ele mesmo relatou as diversas ocasiões nas quais ia visitar alguns de seus pacientes e, ao chegar às suas portas, sacava seu molho de chaves do bolso, na tentativa de abrir a porta, como se fosse a sua própria casa. Independentemente das possíveis interpretações, o simples costume de retirar o molho de chaves 
diante de sua porta de casa não seria um ato condicionante que levaria sistematicamente a esse comportamento diante de toda e qualquer porta. Ou seja, da mesma forma que acima, algum valor, relativo ao seu próprio lar, emerge deslocado e tende a trazer algum conteúdo inconsciente à tona, à sua consciência ${ }^{23}$.

Apesar da ausência de registro científico específico de ato-falho aplicado em um contexto qualitativo ligado à Atenção Farmacêutica, destaca-se uma interessante ilustração da importância e do poder transformador do ato falho (de uma ação) em um estudo de análise de implicação do investigador em uma intervenção ${ }^{25}$. $\mathrm{Na}$ situação, a autora destaca que durante a sequência dos grupos de discussão dos quais participava, os investigadores haviam identificado grande dificuldade em se apropriarem de um determinado fazer inventivo como um know-how próprio e que sempre tais tipos de dificuldades eram regularmente trabalhadas para superação dentro do próprio grupo. Enquanto o problema era tratado, estes investigadores participaram da organização de um evento científico no qual esta experiência de discussão iria ser apresentada.

$\mathrm{O}$ ato falho cometido pela autora foi: em lugar de designar alguém do grupo para fazer tal apresentação, ela delegou a atribuição a uma exgestora, não pertencente ao grupo. Como consequência de tal ato falho (segundo a própria autora) houve imediata reação do grupo diante de semelhante "traição". Entretanto, posteriormente, ao implicar-se com seu ato falho em uma análise coletiva com seu grupo, a autora descreveu significativos ganhos para todos, que culminaram com a desmistificação do lugar de despossuídos de um saber próprio dos participantes da equipe e com a descristalização da ideia de “instituição saber" até então associada à figura do especialista-pesquisador-acadêmico encarnada pela autora ${ }^{25}$.

Com este exemplo de ação inconsciente aparentemente inofensiva (a autora não descreveu seu ato como consciente), pode-se avaliar a amplitude e os desdobramentos de um erro "não intencional" em termos de consequências surpreendentes tanto para o indivíduo que o comete quanto para o grupo que o observa, uma vez que a devida relevância ao ato falho seja dada. É importante frisar que apenas quando o indivíduo se implicou com seu ato falho no contexto do grupo afetado que as barreiras existentes às discussões específicas sobre saberes emergiram e permitiram aos membros falar propriamente de seus descontentamentos.
Neste sentido, são frequentes os estudos de Atenção Farmacêutica que identificam barreiras de comunicação entre farmacêutico comunitário e médico, normalmente caracterizadas na imagem percebida (pela comunidade em geral) do farmacêutico apenas como um vendedor; na dificuldade de acessibilidade entre diferentes profissionais de saúde; e até mesmo nas questões de hierarquia entre médico e farmacêutico ${ }^{26}$. Este tipo de estudo é extremamente robusto na identificação dos problemas ligados a implantação de um sistema de Atenção Farmacêutica interdisciplinar, mas, permanece refém de um discurso conclusivo que aponta apenas pela necessidade consciente de treinamento de alunos de graduação e pós-graduação em saberes que melhorem o entendimento mútuo, a confiança e a comunicação ${ }^{26}$. Assim, pode-se imaginar que a inclusão da análise de relatos falados ou escritos de atos falhos nestes tipos de estudos possa trazer elementos valiosos para a superação de diversas barreiras à implantação de um modelo de Atenção Farmacêutica.

A sua vez, a inclusão da análise deste tipo de formação de compromisso na escuta do farmacêutico e na atenção ao seu paciente pode resultar em uma forma de vencer barreiras de relacionamento, promovendo a solução de problemas de adesão e disposição para retirar dúvidas de tratamentos medicamentosos, sobretudo daqueles que tendem a rotular o paciente, como no caso de pacientes usuários de antidepressivos ${ }^{27}$.

A título prático, o Farmacêutico deve considerar as seguintes características utilizadas por Freud e que circunscrevem as condições mínimas de um ato falho, para que se possa considerá-lo relevante: (i) não deve exceder certas medidas, sendo considerado dentro de um campo de "variação do normal"; (ii) ter um caráter de perturbação momentânea e passageira, ou seja, algo que se tenha executado antes de maneira mais correta ou que acredite ser capaz de realizar corretamente em outro momento e (iii) ao ser corrigido por outra pessoa, é preciso o reconhecimento de imediato da exatidão da correção e a inexatidão do próprio processo psíquico. Enfim, ao perceber um ato falho, não sentir no paciente qualquer motivação para ele, mas antes estar tentado em explicá-lo pela "desatenção" ou ainda como uma "casualidade" 24 . Estas recomendações, ou melhor, observações a respeito das características que cercam as percepções sobre o ato falho tendem a esclarecer algumas sensações humanas que até mesmo os mais reticentes podem compartilhar. O sentido de "dentro do campo de 
variação do normal" vem ressaltar o sentido trivial que o ato falho traz: um representante de conteúdo inconsciente muito bem disfarçado. Por outro lado, a sutileza não é grande o suficiente para deixar de chamar total atenção, uma vez que a surpresa se dá no momento em que ele ocorre e se percebe quando já foi realizado tal ato sem qualquer falha. Além disso, a surpresa é reiterada pela ação de outra pessoa que também é capaz de flagrar o ato falho cometido. Porém, mesmo que todos estes elementos passem despercebidos aos demais, ainda assim o autor do falho terá um resquício de curiosidade que permanecerá em sua consciência, mas que tenderá a ser resolvida pela classificação de desatenção ou acaso. Em outras palavras, todos estes elementos conspiram para que haja um quase-que-perfeito compromisso: um acordo equilibrado entre o desejo de se fazer consciente e o seu respectivo impedimento interposto pela ação da censura.

\section{Do chiste}

Em 1905, Freud publicava um texto dedicado aos chistes e sua relação com o inconsciente ${ }^{28}$. Este estudo consagrado ao chiste pelo chiste lhe permitiu analisá-lo através do que lhe era intrínseco, sua coerência interna, e não a partir de algo que estivesse fora ou que lhe fosse estranho ${ }^{29}$. Até então, o chiste era tido apenas subordinado ao cômico, seja caricatura ou simples desvelar de algo escondido à intencionalidade, pensado como contraste ou jogo entre "ideias"; ou, ainda, à satisfação contemplativa e desinteressada do "espírito" no gracejo ${ }^{29}$.

Freud avançou sobre outros pontos de vistas do chiste que em certos aspectos aparecem interrelacionadas: o contraste de representação, o sentido no sem sentido (nonsense), e o desconcerto e iluminação (esclarecimento) ${ }^{28}$ apontando para algo além do aspecto cômico em si. O chiste é descrito como dotado e produzido a partir de uma necessidade psicológica.

A exemplo do ato falho, o chiste também apresenta características que não permitem em um primeiro olhar encontrar-lhe sentido. Na fração de segundo na qual se nota o enunciado chistoso, e aparentemente se agrega sentido, imediatamente é refutado: isso significa que em algum grau a censura do sujeito atua. Deste modo, o sujeito pode permanecer relativamente satisfeito com o lado cômico, considerando-o um ato sem significância maior e nulo; ou pode avançar em sua percepção buscando nesse fato disfarçado seu verdadeiro sentido que lhe chega à consciên- cia. Em outras palavras, o Farmacêutico não deverá privar-se de tirar proveito e avaliar o peso e significância do chiste de seu paciente, que pode ser considerado a mais social das formações do inconsciente ${ }^{29}$.

Os instrumentos de linguagem que estão à disposição para criação de um enunciado chistoso podem ser resumidos em grupos como: condensação; o múltiplo uso de uma mesma palavra e $o$ duplo sentido ${ }^{28}$. O uso destas técnicas para o desmonte do chiste é capaz apenas de eliminar todo o seu poder chistoso e qualquer tentativa de explicar uma piada terminará por retirar sua graça. De fato, há um conteúdo oculto no chiste que não pode ser desvelado através de sua simples desconstrução técnica. Este conteúdo oculto pode ser aquele presente no inconsciente do sujeito, mas, de um ponto de vista prático, não pode ser acessado diretamente. Indiretamente, porém, existe uma dica para aquele que escuta (p.ex. o farmacêutico) um chiste: ficar atento para certa característica que é demonstrada por quem o conta: a fruição ou prazer que the é proporcionado neste ato.

Neste sentido, os chistes inocentes têm maior valor, em termos de conteúdo inconsciente, do que aqueles tendenciosos ${ }^{28}$. Os chistes tendenciosos teriam um fim específico, baseado na palavra e/ou na técnica e não revelariam o mesmo que um chiste inocente.

Uma vez mais, é tarefa difícil apontar exemplos práticos do chiste e seu valor em estudos qualitativos. Curiosamente, vale destacar o registro de chiste realizado por Líria Maria Betti$\mathrm{ol}^{30} \mathrm{em}$ seu livro intitulado "Saúde e Participação Popular em Questão: o Programa Saúde da Família”, o qual foi posteriormente comentado por Possamai e Dacoreggio ${ }^{31}$. Bettiol relacionou o slogan adotado pelo Ministério da Saúde para o Programa Saúde da Família (PSF) "porta de entrada para o SUS" com a canção "A casa" de Vinícius e Tonga cuja letra começa com: "Era uma casa, muito engraçada, não tinha teto, não tinha nada, ninguém podia subir na rede, porque na casa não tinha parede..." ${ }^{\prime 3}$. Possamai e Dacoreggio $^{31}$, em artigo sobre a habilidade de comunicação com o paciente no processo de Atenção Farmacêutica, invocaram o referido chiste quando analisavam a forma de como o farmacêutico poderia colaborar com a implantação da Assistência Farmacêutica no SUS a partir da sua incorporação às equipes do Programa Saúde da Família (PSF). Estes autores atribuíram uma possível interpretação da motivação do chiste de Bettiol a causas relacionadas ao processo políti- 
co nacional e à cultura política centralizadora brasileira, cujas consequências eram presentes nos vários níveis de organização dos sistemas locais de saúde analisados ${ }^{31}$.

Existe neste exemplo de chiste pelo menos uma dimensão que deve ser levantada, a condensação, uma vez que a autora não transcreveu ou citou a íntegra da letra da música, mas apenas as primeiras estrofes. Entretanto, o fim da música revela uma estrofe que talvez expressasse melhor o afeto inconsciente da autora, mas que estaria sob efeito de censura, sem poder emergir literalmente: "Mas era feita com muito esmero, na rua dos bobos, número zero”. Uma interpretação desta condensação poderia ser que talvez, este fim contundente teria sido forte demais (angustiante para ser escrito e falado), mas seria o que melhor representa o sentimento pessoal de Bettiol quanto às políticas públicas nacionais ligadas à saúde.

Sem dúvida, cientes de que se trata de mais uma interpretação especulativa, o objetivo aqui é o de apontar a necessidade de uma análise mais criteriosa dos elementos deste tipo de formação de compromisso assim como do ato falho que estão fora do alcance do observador quando apenas presentes em um simples relato escrito.

\section{Da interpretação}

Neste ponto, deve-se ressaltar a importância não somente da interpretação do chiste/ato falho como aquela produzida no chiste/ato falho. $\mathrm{O}$ que foi apresentado até agora está limitado ao que se pode depreender $d a$ análise posterior e não na análise no momento nascente, no qual a formação de compromisso é produzida. No exemplo do chiste, os elementos no instante da produção e suas implicações estão perdidos, ou unicamente acessíveis a partir da implicação da autora Bettiol com o(s) destinatário(s) de seu chiste àquele momento, assim como o grau de fruição da autora à época e mesmo nos desdobramentos até os dias de hoje. Os elementos perdidos estavam disponíveis no momento da produção do chiste para um ou mais destinatários específicos e que podem ter maior valor, posteriormente, para interpretações do que qualquer tentativa. Isto, porque, a exemplo do ato falho, o chiste implica tanto quem faz o chiste quanto aquele destinatário que o escuta, são formações do insconsciente ${ }^{28}$.

A natureza deste exemplo de chiste, o contexto, seus destinatários e possíveis implicações no meio, desdobramentos, inclusive nos destinos da sequência da redação do próprio livro de Bettiol a partir dele, não estão inequivocamente definidos (talvez até para a própria autora) e têm valor inconsciente precioso para o entendimento das questões envolvendo a autora e a temática acerca da sua visão sobre o PSF.

$\mathrm{O}$ que se resgata aqui é a ideia da interpretação na análise, na qual a presença do farmacêutico (ou observador) é crítica e o que torna possível que a interpretação ocorra na cena analítica, envolvendo a relação transferencial, na qual paciente e farmacêutico (analista) são implicados.

No entanto, Lo Bianco ${ }^{32}$ ressalta que apesar da interpretação depender desta implicação do analista, ela não deve se manifestar pela intencionalidade desse mesmo analista, que profere uma palavra interpretativa a respeito de uma ou outra formação de compromisso. Na relação com o paciente existe um manejo do desejo inconsciente e ao mesmo tempo o reconhecimento por parte do analista do quanto o paciente pode ou não suportar a sua angústia e o que é insuportável para o paciente expressar em nível conscien$\mathrm{te}^{32}$. Da mesma maneira, Lo Bianco pensa a interpretação no seu laço com a transferência entre paciente e observador (analista ou farmacêuti$\mathrm{co})^{32}$. Ainda segundo a autora, a interpretação que surge em análise se apresenta entre o analista e o analisando em um estado limite no qual o paciente só revela em palavra aquilo que não torna seu discurso insuportavelmente angustiante e depende do lugar ocupado pelo analista ${ }^{32}$. Ela emerge no momento da análise em seu "sentido forte”, isto é, no momento da transferência, no qual está em jogo a presença do analista frente ao analisando. Assim, dependendo do momento e de como o paciente "veja" seu analista ou seu farmacêutico, deve-se pensar as flutuações que podem sofrer o curso das interpretações ${ }^{32}$. Lo Bianco destaca que é na relação transferencial que reside o determinante da interpretação. Ela reitera que não se trata de uma simples interpretação dada por uma "correta avaliação", mas, ao contrário, da inserção do analista (farmacêutico) no que podemos considerar como o modo de funcionamento inconsciente em operação em um dado paciente ${ }^{32}$.

Assim, o valor de um mesmo chiste ou ato falho cometido por um mesmo paciente diante de diferentes farmacêuticos pode ter valor psicológico completamente distinto. Ou ainda, o mesmo chiste para o mesmo farmacêutico, mas em momentos diferentes, pode representar conteúdo psíquico inconsciente completamente distinto. Basta imaginar que para certos indivíduos o 
papel (ou melhor, o lugar onde é colocado) do farmacêutico é variável: ora comerciante, ora conselheiro, etc. Portanto, é tão importante o Farmacêutico saber em qual lugar ou papel ele tem para seu paciente, uma vez que também terá de manejar angústias de seu paciente e deverá estar apto a receber as informações neste limite de relação apontado por Lo Bianco ${ }^{32}$.

Deste modo, pode-se entender que atos falhos e chistes perfazem um conjunto de formações de compromisso que são utilizadas frequentemente como estratégia de sobrevivência psíquica, um modo de resgate energético consagrado ao "viver-bem" em comunidade, cujos conteúdos estão muito mais além de uma simples consciente e intencional interpretação e não podem ser simplesmente descartados por um observador.

\section{Considerações finais}

O presente trabalho pretendeu realizar um breve percurso através de alguns conceitos da metapsicologia freudiana a fim de familiarizar o farmacêutico com a técnica da Atenção Flutuante e seu embasamento teórico. Além disso, ressaltou-se a importância de elementos inconscientes do discurso de um paciente na obtenção de informações valiosas para o entendimento da sua relação com o seu farmacêutico e até mesmo as possíveis implicações envolvidas em maior ou menor adesão a um tratamento. Estes conteúdos são relevantes tanto para o aspecto individual existente na Atenção Farmacêutica como para incrementar o rol de ferramentas na obtenção de dados em pesquisas qualitativas que impliquem observação participante. Os conceitos aqui levantados tendem a oferecer opções às estratégias diretivas para a superação de problemas relativos à sua doença ou seu tratamento, uma vez que entende-se o paciente como ser dotado de subjetividade e que não se dispõe a normatização. De fato, a falta de confiança no profissional farmacêutico, a dificuldade de adesão e continuidade ao tratamento, problemas com tóxico-dependência, entre outros, somente poderão ser superados a partir de uma escuta e acolhimento mais sensíveis em relação ao paciente. Paulon ${ }^{25}$ já destaca que desde a década de 1960 múltiplas abordagens para a compreensão dos fenômenos sociais já buscavam reunir contribuições da filosofia marxista e da psicanálise na valorização dos aspectos inconscientes que passariam a ser considerados nos processos de investigação. A toda a efervescência de ideias nascidas à época, Paulon ${ }^{26}$ acrescenta a necessidade de ir além da inclusão do pesquisador no campo das observações, ou da simples problematização da relação pesquisador-campo de investigação: o imperativo em aprofundar, também, as concepções de subjetividade e da ciência que orientam a investigação. Este aprofundamento, por sua vez, implica encarar uma escolha ética apontada por Guattari $^{33}$ que coloca em oposição a objetivização e a cientifização da subjetividade em relação à sua apreensão em uma dimensão criativa processual. É justamente com este tipo de abordagem da apreensão processual da subjetividade que os conceitos metapsicológicos aqui apresentados se articulam. As implicações da técnica de Atenção Flutuante como as possíveis interpretações de atos falhos e chistes se dão em um processo (ou relação) que é construída entre paciente e farmacêutico, com todos os possíveis eventos que modulem ou modifiquem esta relação. Mais uma vez destaca-se o farmacêutico como depositário dos conteúdos transferenciais do paciente e passível de ser tomado como profissional mutante possuindo múltiplos papéis. Diante deste aspecto mutável, Paulon ${ }^{25}$ aponta para a intervenção como "processos mutantes" que não a resume ao simples encontro entre sujeitos da investigação versus objetos investigados, como se fosse um processo antecipável. Neste plano, "a intervenção deve guardar sempre a possibilidade do ineditismo da experiência humana e o pesquisador a disposição para acompanhá-la e surpreender-se com ela"25. Finalmente, reitera-se que a Atenção Flutuante pode servir como mais uma ferramenta para incrementar os elementos de disposição do farmacêutico em colocar-se suscetível para a surpresa e dela tirar proveito, em benefício daquele que assiste e da possibilidade de abrir mais uma porta para o entendimento de suas funções como profissional da saúde. 


\section{Colaboradores}

M Pádula foi responsável pela concepção, pesquisa e redação final do artigo. AV Pinto participou da elaboração final do artigo e revisão bibliográfica. GC Matos, DT Siqueira e RC Vieira participaram da revisão crítica do artigo.

\section{Referências}

1. Brasil. Parecer CNE/CES 1.300/2001, Ministério da Educação, Câmara de Ensino Superior, Diretrizes Curriculares, Diário Oficial da União. 2001; 7 dez.

2. Brasil. Ministério da Saúde (MS). Política Nacional de Promoção da Saúde. Brasília: MS; 2006.

3. Leite SN. Quê "promoção da saúde"? Discutindo propostas para a atuação do farmacêutico na promoção da saúde. Cien Saude Colet 2007; 12(Supl. 6):1-2.

4. World Health Organization (WHO). The role of the pharmacist in the health care system: preparing the future pharmacist. Report of a third WHO consultative group on the role of the pharmacist. Vancouver, Canada, 27-29 August, 199. Geneva: WHO; 1997.

5. World Health Organization (WHO). International Training Course on Promoting Rational Drug Use in the Community. Japur: WHO; 2010.

6. Angonesi D. Dispensação farmacêutica: uma análise de diferentes conceitos e modelos. Cien Saude Colet 2008; 13(Supl.):629-640.

7. Cipolle R, Strand L, Morley P. El ejercicio de la atención farmacéutica. Madrid: McGraw-Hill Interamericana; 2000.

8. Organização Pan-americana de Saúde (OPAS). Consenso Brasileiro de Atenção Farmacêutica: Proposta. Brasília: OPAS, MS; 2002.

9. Freud S. Pulsiones y destinos de pulsión (1915), La repressión (1915), Lo inconsciente (1915) In: Freud S. Obras Completas. XIV. Contribución a la historia del movimiento psicoanalítico. Trabajos sobre metapsicologia y otras obras (1914-1916). Buenos Aires: Amorrortu; 2003. p. 105-214.

10. Rios IZ. Humanização e ambiente de trabalho na visão de profissionais da saúde. Saude Soc 2008; 17(4):151-160.

11. Teixeira MZ. Bases psiconeurofisiológicas do fenômeno placebo-nocebo: evidências científicas que valorizam a humanização da relação médico-paciente. Rev Assoc Med Bras 2009; 55(1):13-18.

12. Laplanche J, Pontalis JB. Vocabulário da Psicanálise. 4a Edição. Itajaí: Martins Fontes; 2004.

13. Freud S. Más allá del princípio de placer (1920). In: Freud S. Obras Completas.XVIII. Más allá del principio de placer. Psicología de las masas y análisis del yo y otras obras $(1920-1922)$. Buenos Aires: Amorrortu; 2003. p. 2-62.

14. Oliveira DR, Varela ND. La investigación cualitativa en Farmacia. Aplicación en la Atención Farmacéutica. Rev Bras Cienc Farm 2008; 44(4):763-772

15. Rodríguez G, Gil J, García E. Metodología de la investigación cualitativa. La Habana: Editorial Félix Varela; 2004.

16. Gallego JC. Observación, entrevista y grupo de discusión: el silencio de tres prácticas de investigación. Rev Esp Salud Pública 2002; 76(5):409-422.

17. Acción Internacional para la Salud. Latinoamérica \& Caribe. ¿Farmacia Social?. The Chronic ill. [periódico na Internet]. 2003 [acessado 2012 nov 22]; (3). Disponível em http://www.aislac.org/index.php? option=com_content\&view=article\&id=267:ifarmaciasocial\&catid=30: noticias-2003\&Itemid $=158$. 
18. Freud S. Consejos al médico sobre el tratamiento psicoanalítico (1912). In: Freud S. Obras Completas. XII. Sobre um caso de paranoia descrito autobiograficamente (Schreber). Trabajos sobre técnica psicoanalítica y otras obras $(1911-1913)$. Buenos Aires: Amorrortu; 2003. p. 107-120.

19. Souza CRA, Coelho DM. O neutro em psicanálise: da técnica à ética. Fractal: Rev Psicol 2012; 24(1):95110.

20. Taylor SJ, Bogdan R. Introducción a los métodos cualitativos de investigación. Buenos Aires: Paidós; 1986.

21. Freud S. Obras completas. II. Estudios sobre la histeria (Breuer y Freud) (1893-1895). Buenos Aires: Amorrortu; 2003.

22. Lacan J. El seminário, libro V: las formaciones del inconsciente (1957-1958). Buenos Aires: Paidós; 1999.

23. Freud S. Obras Completas. VI Psicopatología de la vida cotidiana (1901). Buenos Aires: Amorrortu; 2003.

24. Lins T. Impulsividade na teoria psicanalítica: do ato falho à passagem ao ato [dissertação]. Rio de Janeiro: Pontificia Universidade Católica do Rio de Janeiro; 2012.

25. Paulon SM. A análise de implicação como ferramenta na pesquisa-intervenção. Psicol Soc 2005; $17(3): 18-25$.

26. Hughes CM, McCann S. Perceived interprofessional barriers between community pharmacists and general practitioners: a qualitative assessment. $\mathrm{Br} \mathrm{J}$ Gen Pract 2003; 53(493):600-606.

27. Garfield S, Smith FJ, Francis AS. Roles for pharmacists in the treatment of depression in primary care. Int J Pharm Pract 2002; 10(Supl. S1):R59

28. Freud S. Obras Completas. VIII. El chiste y su relación con lo inconsciente (1905). Buenos Aires: Amorrortu; 2003.

29. Freire AB, Costa CAR. O literal e a surpresa: os "estágios preliminares do chiste". Ágora 2008; 11(Supl. 2):235-251.

30. Bettiol LM. Saúde e participação popular em questão: o Programa Saúde da Família. São Paulo: Unesp; 2006.

31. Possamai FP, Dacoreggio MS. A habilidade de comunicação com o paciente no processo de atenção farmacêutica. Trab. Educ. Saude 2008; 5(3):473-490.

32. Lo Bianco AC. Elementos para uma metapsicologia da interpretação em análise. Psicol Reflex Crit 1999; 12(3).

33. Guattari F. Linguagem, Consciência e Sociedade. In: Guattari F, Deleuze G. Saúde Loucura 2. São Paulo: Hucitec; 1991.

Artigo apresentado em 18/08/2012

Aprovado em 21/10/2012

Versão final apresentada em 30/10/2012 